Revue bibliographique pour le domaine irano-aryen

\title{
Vito Messina. "A Watchtower of the late Sasanian period on the outskirts of Veh Ardashir (Coche)"
}

\section{Rika Gyselen}

\section{(2) OpenEdition \\ 12 Journals}

\section{Édition électronique}

URL : http://journals.openedition.org/abstractairanica/49628

DOI : 10.4000/abstractairanica.49628

ISBN : 1961-960X

ISSN : 1961-960X

Éditeur :

CNRS (UMR 7528 Mondes iraniens et indiens), Éditions de l'IFRI

Référence électronique

Rika Gyselen, « Vito Messina. "A Watchtower of the late Sasanian period on the outskirts of Veh Ardashir (Coche)" ", Abstracta Iranica [En ligne], Volume 40-41 | 2019, document 22, mis en ligne le 30 octobre 2019, consulté le 17 avril 2021. URL : http://journals.openedition.org/abstractairanica/49628 DOI : https://doi.org/10.4000/abstractairanica.49628

Ce document a été généré automatiquement le 17 avril 2021.

Tous droits réservés 


\title{
Vito Messina. "A Watchtower of the late Sasanian period on the outskirts of Veh Ardashir (Coche)"
}

\author{
Rika Gyselen
}

\section{RÉFÉRENCE}

Vito Messina. "A Watchtower of the late Sasanian period on the outskirts of Veh Ardashir (Coche)" Paolo de Vingo (ed.). Le Archeologie di Marilli. Miscellanea di studi in ricordo di Maria Maddalena Negro Ponzi Mancini. Alessandria: Edizioni dell'Orso, 2018, ( ( Mnème », Documenti, culture, storia del Mediterraneo e dell'Oriente Antico, 12), p. 95-104

1 Dans le cadre des fouilles italiennes à Séleucie (1964-1989) un bâtiment carré fut découvert. Il fut bâti à l'époque sassanide tardive (datation grâce à un trésor monétaire de Khusraw II) au-dessus du théâtre grec de la ville et était entouré d'un mur de forme elliptique d'environ $90 \mathrm{~m}$ de diamètre. Une étude comparative avec d'autres bâtiments analogues conforte l'idée qu'il s'agit d'un tour de guet.

\section{AUTEURS}

\section{RIKA GYSELEN}

CNRS, Mondes iranien et indien 